\title{
Simulations and experiments of stochastic characteristics for collective short fatigue cracks in steels
}

\author{
Y. HONG, L. ZHENG and Y. QIAO
}

State Key Laboratory of Non-linear Mechanics (LNM), Institute of Mechanics, Chinese Academy of Sciences, Beijing 100080, China

Received in final form 22 September 2001

A B S TRACT Stochastic characteristics prevail in the process of short fatigue crack progression. This paper presents a method taking into account the balance of crack number density to describe the stochastic behaviour of short crack collective evolution. The results from the simulation illustrate the stochastic development of short cracks. The experiments on two types of steels show the random distribution for collective short cracks with the number of cracks and the maximum crack length as a function of different locations on specimen surface. The experiments also give the variation of total number of short cracks with fatigue cycles. The test results are consistent with numerical simulations.

Keywords collective evolution; crack number density; short fatigue cracks; stochastic characteristics.

NOMENCLATURE

Correspondence: Youshi Hong, State Key Laboratory of Non-linear Mechanics (LNM), Institute of Mechanics, Chinese Academy of Sciences, Beijing 100080, China. E-mail: hongys@imech.ac.cn

$t=$ time
$A(c, t, x)=$ crack growth rate at local area $x$

$A_{0}(c)=$ average part of crack growth rate

$A_{\mathrm{d}}=$ crack growth rate at $c=1$

$c=$ nondimensional crack length

$c_{\max }=$ maximum crack length for a local area

$\tilde{c}_{\max }=$ largest crack length in the whole area of observation

$d=$ average ferrite grain size

$\bar{d}=$ normalized average grain size

$D_{0}(t, x)=$ zero-th order of damage moment or the number of total cracks

$\tilde{D}_{0}=$ number of total cracks in the whole area of observation

$L(c), L^{*}(c)=$ variables for stochastic process

$n_{\mathrm{N}_{0}}(c)=$ average part of crack nucleation rate

$n(c, t, x)=$ crack number density at local area $x$

$n_{\mathrm{N}}(c, t, x)=$ crack nucleation rate at local area $x$

$N=$ number of loading cycles

$N_{\mathrm{d}}=$ number of loading cycles for short crack regime

$N_{\mathrm{f}}=$ number of loading cycles to fracture

$N_{\mathrm{g}}=$ nondimensional coefficient

$P_{\mathrm{C}}=$ pearlite fraction

$W_{1}(x), W_{2}(x)=$ white noise representing two independent stochastic processes

$\eta, \xi, p, q=$ material constants

$\sigma_{\mathrm{y}}=$ yield stress

$\sigma_{\max }=$ maximum stress

\section{INTRODUCTION}

It has been revealed that, the initiation and the propagation of short fatigue cracks in most metallic materials present collective evolution behaviour. The number of short fatigue cracks increases with fatigue cycles and the 
extent of fatigue damage depends on the total number of short cracks. ${ }^{1-6}$ For this situation, we adopted the method of the equilibrium of crack number density to describe such an evolutionary process. ${ }^{7-9}$ The basic concept of the model is that, at certain time duration, the number of cracks with a given length is because of two aspects: (a) crack nucleation; and (b) crack growth. In previous studies, the evolution of short cracks was often assumed uniform throughout the gauge area of a specimen. However, during a fatigue process, the initiation and the growth of short cracks are always randomly distributed. In some local areas, short cracks appeared with high density; simultaneously in some other areas, no short crack damage occurred. ${ }^{1-6}$ This suggests that the collective damage of short fatigue cracks is a stochastic process.

In this paper, the collective development of short fatigue cracks in different local fields is described in the light of local crack number density (LCND). By considering the influence of damage and the stochastic fluctuation of local material properties, the equilibrium equation of LCND is established. The simulation of short crack damage is performed by the equilibrium equation with LCND concept. The progression for the maximum crack length and the number of cracks in different locations demonstrates the stochastic development of short cracks. The simulations also give a comparison between the mean-field theory and the stochastic analysis. An experimental investigation was correspondingly conducted, in which two types of steels were tested. One was a series of structural steels with five grades of carbon content. The other was a stainless steel with two grades of grain size. In addition to the effect of the pearlite fraction and the grain size on the short fatigue crack damage, the experimental results show the stochastic development for the maximum crack length and the number of cracks in different locations. The results also show the increase of the total number of cracks against fatigue cycling. The tendency of the experimental measurements is in good agreement with the theoretical simulations.

\section{STOCHASTIC MODEL AND NUMERICAL SIMULATIONS}

Denote $n(c, t, x)$ as LCND to describe the fatigue damage, which represents the crack number density of a local area $x$. Such an area is small enough comparing with the macro-scale of material, but it contains enough number of short cracks to fulfil the requirement by the LCND analysis method. The evolution equation is: ${ }^{10}$

$\frac{\partial}{\partial t} n(c, t, x)+\frac{\partial}{\partial c}[A(c, t, x) n(c, t, x)]=N_{\mathrm{g}} n_{\mathrm{N}}(c, t, x)$.
Equation [1] is established based on the concept that the total number of short cracks in area $x$ is determined by both the crack nucleation and the crack growth in the area, which describes the equilibrium of LCND in the phase space. The second term on the left side of Eq. [1] represents the flow of LCND, which is attributed to the crack growth in area $x$, while the term on the right side represents the influence induced by crack nucleation in area $x$. The research in Ref. [11] indicated that the damage extent because of the collective short cracks was dominated by the zero-th order of damage moment $D_{0}(t, x)$, i.e. the number of total cracks. If only the correlation between the nearest neighbouring cracks is taken into account, one may write

$A(c, t, x)=A\left[c, x, D_{0}(t, x), \frac{\partial D_{0}(t, x)}{\partial x}\right]$,

and

$n_{\mathrm{N}}(c, t, x)=n_{\mathrm{N}}\left[c, x, D_{0}(t, x), \frac{\partial D_{0}(t, x)}{\partial x}\right]$

Consider that the influence caused by damage cumulation and crack length in the above equations can be treated separately and assume that the number of total cracks can be expressed as a power-law type. Such that,

$A(c, t, x)=\left[A_{0}(c)+L(c) W_{1}(x)\right]\left[\eta D_{0}^{\xi}(t, x)\right]$,

and

$n_{\mathrm{N}}(c, t, x)=\left[n_{\mathrm{N}_{0}}(c)+L^{*}(c) W_{2}(x)\right]\left[p D_{0}^{q}(t, x)\right]$.

Combining Eqs (4), (5) and (1) one may obtain the following stochastic equation for the problem concerned:

$$
\begin{aligned}
& \frac{\partial}{\partial t} n(c, t, x)+\eta_{1}\left\{t\left[a+b W_{2}(x)\right]\right\}^{\frac{\xi}{1-q}} \\
& \quad \frac{\partial}{\partial c}\left\{n(c, t, x)\left[A_{0}(c)+L(c) W_{1}(x)\right]\right\} \\
& \quad=N_{\mathrm{g}} p_{1}\left[n_{\mathrm{N}_{0}}(c)+L^{*}(c) W_{2}(x)\right]\left\{t\left[a+b W_{2}(x)\right]\right\}^{\frac{q}{1-q}},
\end{aligned}
$$

where, $\eta_{1}=\eta(1-q)^{\frac{\xi}{1-q}}, p_{1}=p(1-q)^{\frac{\xi}{1-q}}, a=\int_{0}^{\infty} p n_{\mathrm{N}_{0}}(c)$ $\mathrm{d} c$, and $b=\int_{0}^{\infty} p L^{*}(c) \mathrm{d} c$.

In the calculation of Eq. [6], we set $\xi=-q$ $=0.5, \eta=p=1.0$, and $A_{0}(c)$ and $n_{\mathrm{N}_{0}}(c)$ are assumed to be the following forms:

$A_{0}(c)= \begin{cases}1-\left(1-A_{\mathrm{d}}\right) c & (c \leq 1) \\ \bar{d} & (c>1)\end{cases}$ 
$n_{\mathrm{N}_{0}}(c)= \begin{cases}1-\frac{c}{2} & (c \leq 2) \\ 0 & (c>2)\end{cases}$

$L(c)$ and $L^{*}(c)$ in Eq. (6) are assumed with the same form as Eqs (7) and (8). Figure 1 is the result of a simulation showing the stochastic evolution of the maximum crack length $c_{\max }$ for different local areas at different time stages. It is seen that four local areas labelled A, B, $\mathrm{C}$ and $\mathrm{D}$ are four typical evolution sites: area $\mathrm{A}$ - the value of $c_{\max }$ is very small for the whole process; area $\mathrm{B}-c_{\max }$ is small at the beginning of the fatigue damage but it grows up rapidly and becomes a main crack site in the whole field; area $\mathrm{C}$-at this site there is always one of the largest cracks in the whole field; and area D-the crack at this site is one of the largest at the beginning of fatigue process but its growth rate slows down and eventually it cannot act as one of the largest cracks for the whole field. The simulation result shown in Fig. 2 illustrates the distribution of the number of total cracks $D_{0}$ in different local areas for the same simulation as Fig. 1. A small value of $D_{0}$ for areas $\mathrm{A}$ and $\mathrm{B}$ is observed from the beginning to later stages, and a relatively large value of $D_{0}$ is seen at areas $\mathrm{C}$ and D. The results of Figs 1 and 2 display four distinct situations: area $\mathrm{A}$ - unfavourable both for crack initiation and growth; area B — unfavourable for crack initiation but favourable for crack growth; area C-favourable both for crack initiation and growth; and area D-favourable for crack initiation but unfavourable for crack growth. The results demonstrate the stochastic distribution for short crack development caused by the

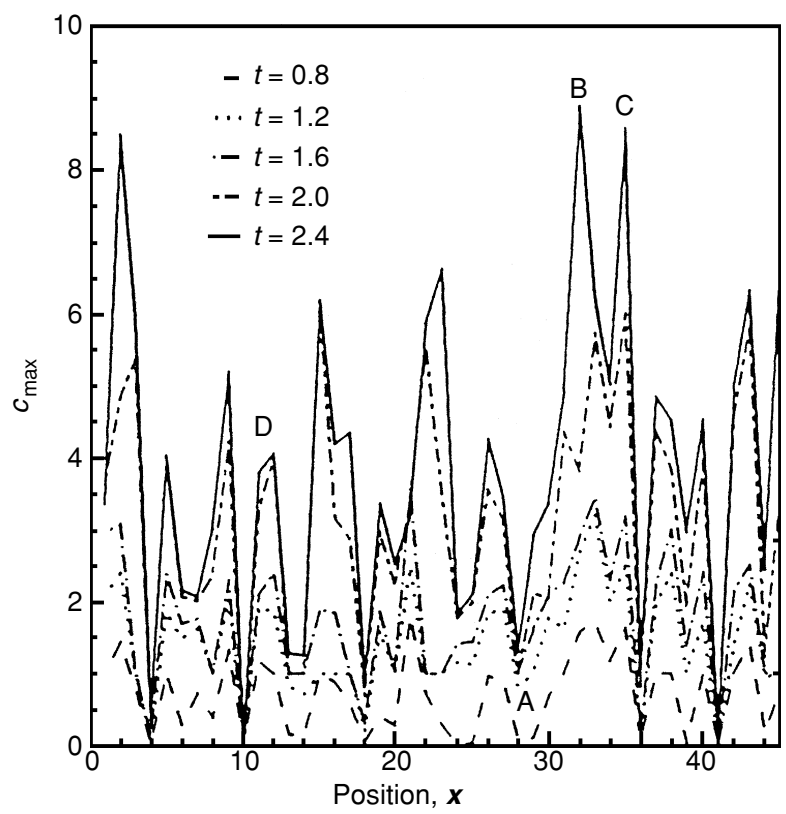

Fig. 1 Evolution characteristics of maximum crack length $c_{\max }$ with time $t$ at different local positions. independent influence of crack initiation and crack growth. These imply that a fast damage development area in the beginning stage of fatigue cycling may not be the location of a main crack, whereas the local area with slow speed of damage development at the beginning may form a main crack leading to final fracture.

Figure 3 shows the results of multiple simulations. The solid curve represents the result of the mean-field theory, i.e. setting $L(c)=0$ and $L^{*}(c)=0$ in Eqs (4) and (5). The dashed curve represents the best-fit result from the data points of stochastic simulations. It is seen from Fig. 3 that with the progression of the fatigue process, the difference between the two cases becomes evident, showing that the value of $\tilde{c}_{\max }$ obtained by the mean-field theory is larger than that obtained by the stochastic simulations. In addition, Fig. 4 shows the correlation between $\tilde{c}_{\max }$ and $\tilde{D}_{0}$, in which the solid curve represents the result from the mean-field theory and the data points denote the results from the stochastic simulations. It is seen that the results from the two methods have the same trend.

\section{TEST MATERIALS AND PROCEDURE}

Two types of test steels were used in this investigation. One type was a series of structural steels with five grades of carbon content. The chemical compositions are listed in Table 1. A specimen of triangular shape ${ }^{1,12}$ was used in fatigue testing for the structural steels. The specimens were annealed so that the microstructure consists of

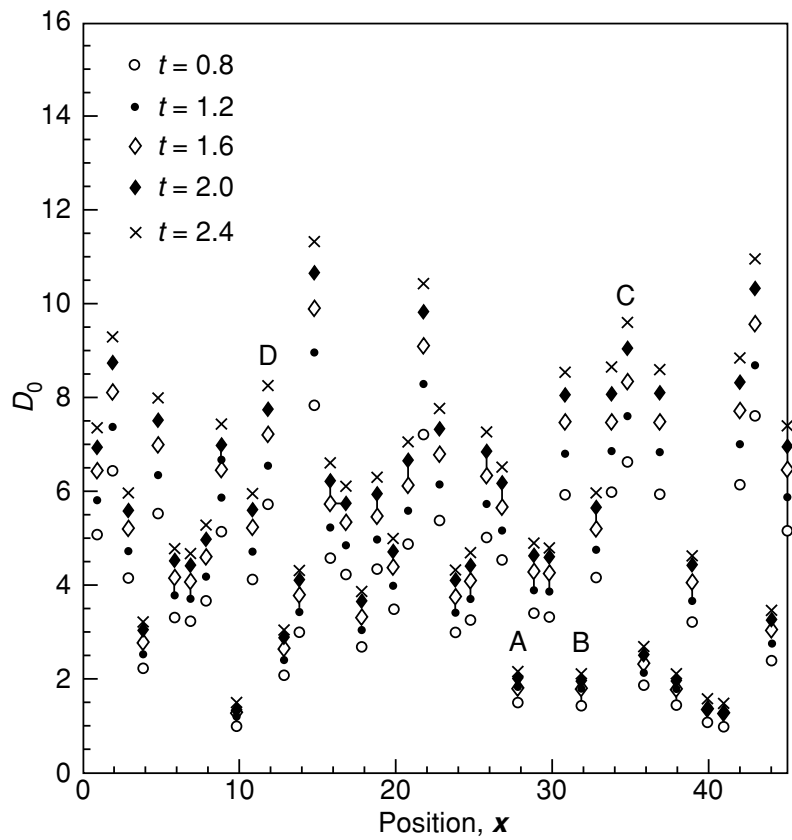

Fig. 2 Evolution characteristics of total number of cracks $D_{0}$ with time $t$ at different local positions. 


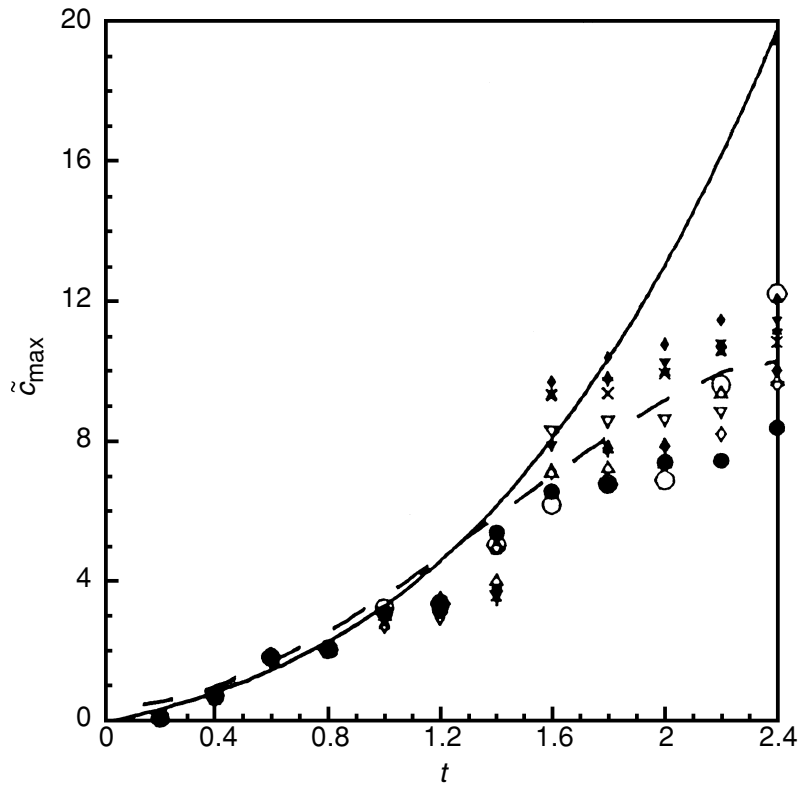

Fig. 3 Evolution characteristics of maximum crack length for the whole field $\tilde{c}_{\max }$ with time $t$ (the solid curve representing the result of a mean-field method, data points showing results of stochastic simulations with dashed curve as regression of simulation data).

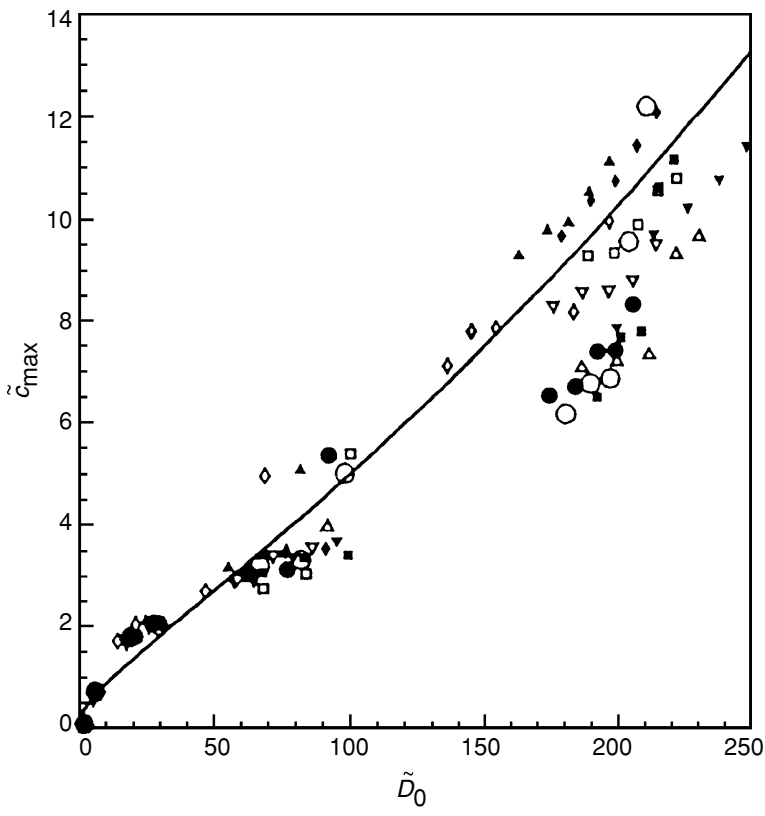

Fig. 4 Relationship between maximum crack length for the whole field $\tilde{c}_{\max }$ and total number of cracks $\tilde{D}_{0}$ (the solid curve representing the result of mean-field method and data points representing results of stochastic simulations).

Table 1 Chemical compositions (wt.\%) of structural steels tested and data for $P_{\mathrm{C}}, d$ and $\sigma_{\mathrm{y}}$

\begin{tabular}{llllllllll}
\hline Steel & $\mathrm{C}$ & $\mathrm{Si}$ & $\mathrm{Mn}$ & $\mathrm{V}$ & $\mathrm{P}$ & $\mathrm{S}$ & $P_{\mathrm{C}}(\%)$ & $d(\mu \mathrm{m})$ & $\sigma_{\mathrm{y}}(\mathrm{MPa})$ \\
\hline $\mathrm{A}_{\mathrm{C}}$ & 0.119 & 0.530 & 1.42 & 0.100 & 0.021 & 0.021 & 13.0 & 31.3 & 299 \\
$\mathrm{~B}_{\mathrm{C}}$ & 0.206 & 0.435 & 1.75 & 0.120 & 0.027 & 0.034 & 24.6 & 32.8 & 424 \\
$\mathrm{C}_{\mathrm{C}}$ & 0.314 & 0.292 & 1.57 & 0.101 & 0.019 & 0.022 & 39.1 & 34.1 & 422 \\
$\mathrm{D}_{\mathrm{C}}$ & 0.382 & 0.327 & 1.58 & 0.101 & 0.022 & 0.025 & 48.1 & 29.4 & 441 \\
$\mathrm{E}_{\mathrm{C}}$ & 0.470 & 0.297 & 1.18 & 0.101 & 0.020 & 0.028 & 59.9 & 21.0 & 405 \\
\hline
\end{tabular}

ferrite and pearlite with different proportions of the two components in relation to corresponding carbon content. The pearlite fraction $\left(P_{\mathrm{C}}\right)$, average ferrite grain size $(d)$ and yield stress $\left(\sigma_{\mathrm{y}}\right)$ are also listed in Table 1.

The other type of test material was a stainless steel with the chemical composition (wt. \%) of $\mathrm{C}=0.098, \mathrm{Si}=0.57$, $\mathrm{Mn}=1.47, \mathrm{P}=0.027, \mathrm{~S}=0.007, \mathrm{Cr}=17.7, \mathrm{Ni}=9.38$. Two groups of specimens $\left(\mathrm{A}_{\mathrm{S}}\right.$ and $\left.\mathrm{B}_{\mathrm{S}}\right)$ with rectangular plate geometry ${ }^{7}$ were given different procedures for heat treatment. The microstructure was austenite (single phase) with the average austenite grain size $(d)$ of group $A_{S}$ $(d=72 \mu \mathrm{m})$ and group $\mathrm{B}_{\mathrm{S}}(d=207 \mu \mathrm{m})$. The yield stress was $250 \mathrm{MPa}$ for group $\mathrm{A}_{\mathrm{S}}$ and $228 \mathrm{MPa}$ for group $\mathrm{B}_{\mathrm{S}}$.

Fatigue testing was performed in a Material Testing System (MTS ) (MTS Systems Corporation, 14000 Technology Drive, Eden Prairie, MN55344-2290, U.S.A.) machine at room temperature. The triangular specimen shown in Fig. 5 was used for the structural steels. The specimen was clamped in a special grip ${ }^{13}$ installed in the MTS machine. The wider end of the specimen was rigidly clamped and the other end was subjected to flexural loading. When reversed cyclic loading was applied, the surface tensile stress within the isosceles triangular part was constant. ${ }^{1,12,13}$ A large gauge area with the same stress condition for monitoring the evolution of short cracks is therefore available. During the fatigue testing, a frequency $f=15 \mathrm{~Hz}$ was applied under the stress ratio $R=-1$. On the other hand, the rectangular plate type specimen with a cross section of $3 \times 10(\mathrm{~mm})$ shown in Fig. 6 was used for the stainless steel. The stress ratio $R=0.1$ and a frequency $f=35 \mathrm{~Hz}$ were applied in such fatigue testing. 

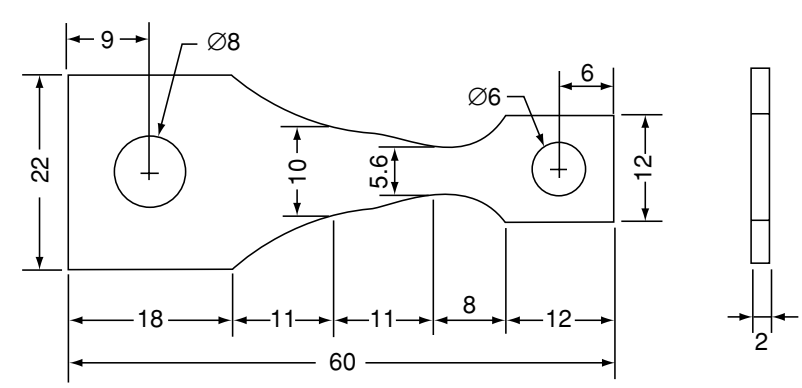

Fig. 5 Specimen of triangular gauge section used in fatigue testing for the tested structural steels (dimensions in $\mathrm{mm}$ ).

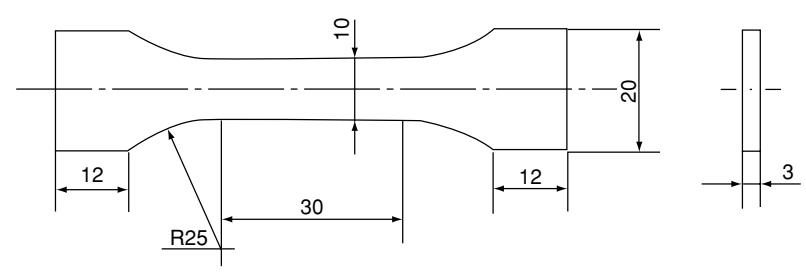

Fig. 6 Specimen of rectangular gauge section used in fatigue testing for the tested stainless steel (dimensions in $\mathrm{mm}$ ).

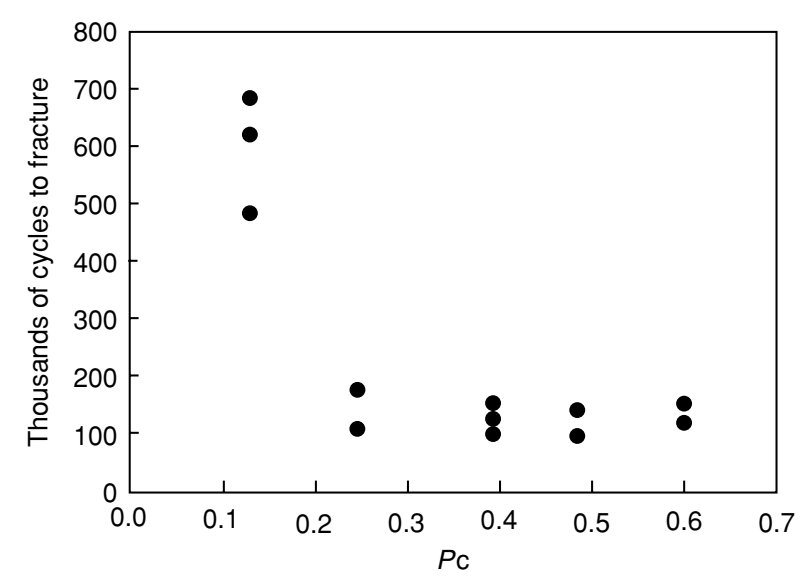

Fig. 7 Fatigue life $N_{\mathrm{f}}$ as a function of pearlite fraction $P_{\mathrm{C}}$ for five groups of steel specimens.

For both the type of specimens, 12-15 observation locations were preset to observe and measure the number of short cracks on the specimen surface. Fatigue cycling was periodically interrupted and the specimen was removed from the test rig. The specimen surface was observed and photographs were taken under an optical microscope with polarized illumination (Reichert-Jung, C. Reichert AG, Hernalser Hauptstrasse 219, A-1170 Wien, Austria). Then the specimen was installed back into the testing machine and the same fatigue loading was again applied. Thus, the photographs taken of the

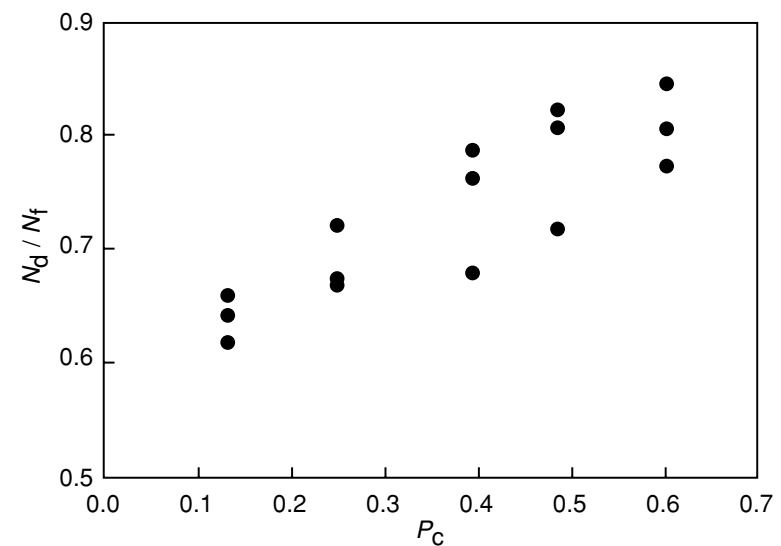

Fig. 8 Ratio of short crack regime to total fatigue life $N_{\mathrm{d}} / N_{\mathrm{f}}$ as a function of pearlite fraction $P_{\mathrm{C}}$ for five groups of steel specimens.

same field traced the initiation and the growth of short fatigue cracks. Fatigue cycles of short crack regime and of total life were measured for the test specimens.

\section{EXPERIMENTAL RESULTS AND DISCUSSION}

It was observed in the experiments that the initiation and the growth of short cracks were within the ferrite domain for the structural steels. The ferrite grain boundary and the pearlite domain are the barriers against short crack development. The observations are of the similar appearance to previous investigations. ${ }^{1,2}$ Figs 7 and 8 show the results of fatigue life as a function of pearlite fraction for the five structural steels which were obtained from fatigue testing at $\sigma_{\max }=1.1 \sigma_{\mathrm{y}}$. Figure 7 indicates that the fatigue life of steel $\mathrm{A}_{\mathrm{C}}$ that possesses the lowest pearlite fraction is much superior to the remaining four groups of specimens, with the data of $N_{\mathrm{f}}$ for $\mathrm{B}_{\mathrm{C}}, \mathrm{C}_{\mathrm{C}}, \mathrm{D}_{\mathrm{C}}$ and $\mathrm{E}_{\mathrm{C}}$ being within the same scatter range. Figure 8 shows an increasing trend of $N_{\mathrm{d}} / N_{\mathrm{f}}$ vs. $P_{\mathrm{C}}$ for the five structural steels, where $N_{\mathrm{d}}$ is the number of loading cycles of the short crack regime that is terminated by a main crack observed on the specimen surface. Figure 8 also indicates that the proportion of short crack regime is between $60 \%$ and $85 \%$, and that when a main crack forms it may last more fatigue cycles for a specimen with lower pearlite fraction.

The initiation and the propagation of short cracks for the test specimens presented typical stochastic characteristics. The random distribution of short cracks was measured in terms of the maximum crack length and the total number of cracks in different locations on specimen surface. As two examples, Fig. 9a-d shows the measurements for steels $A_{C}$ and $E_{C}$, and the situations of the steels $B_{C}, C_{C}$ and $D_{C}$ were of the similar appearance. 
From Fig. 9, one may find typical locations like A, B, $\mathrm{C}$ and D shown in Figs 3 and 4. The tendency of the experimental observations is consistent with the numerical simulations.

Short crack development in the stainless steel tested was observed within the austenite grain domain, and the number of cracks gradually increases with fatigue cycles. Figure $10 \mathrm{a}$ and $\mathrm{b}$ are the measurements of specimens $\mathrm{A}_{\mathrm{S}}$ and $\mathrm{B}_{\mathrm{S}}$ showing the variation of crack number per unit area with the normalized crack length $(c / d)$ and the normalized fatigue cycles $\left(N / N_{\mathrm{f}}\right)$. For group $\mathrm{A}_{\mathrm{S}}$ [Fig. 10a], the data were the measurements of 12 local fields with a total of 186 grains. For group $B_{S}$ [Fig. 10b], the data were cumulated from 15 local fields with a total of 108 grains. The ratio of the maximum stresses $\left(\sigma_{\max }\right)$ to the corresponding yield stresses $\left(\sigma_{\mathrm{y}}\right)$ was 1.5. It is seen from Fig. 10a and $\mathrm{b}$ that a sharp peak develops at $c / d=1$; meaning that the short cracks terminated at grain boundaries. A small proportion of short cracks may pass through the first grain boundary and they may resume a relatively fast growth rate. Only a few short fatigue cracks may overcome the second and the third grain boundary. When a crack grows beyond the fourth grain boundary, it is likely to become a main crack leading to final fracture. One may consider that the short crack regime ends when such a main crack appears. Based on this premise, we obtained that for group $\mathrm{A}_{\mathrm{S}}$ at $\sigma_{\max }=388 \mathrm{MPa}\left(\sigma_{\max } /\right.$ $\left.\sigma_{\mathrm{y}}=1.5\right)$, a main crack first appeared at $N=2.66 \times 10^{5}$ and its final fracture was at $N_{\mathrm{f}}=3.04 \times 10^{5}$. For group $\mathrm{B}_{\mathrm{S}}$ at $\sigma_{\max }=336 \mathrm{MPa}\left(\sigma_{\max } / \sigma_{\mathrm{y}}=1.5\right)$, a main crack first appeared at $N=1.80 \times 10^{5}$ and its final fracture was at $N_{\mathrm{f}}=2.05 \times 10^{5}$. The short crack regime took up a large portion of the total fatigue life, $87.5 \%$ for group $A_{S}$ and $87.8 \%$ for group $\mathrm{B}_{\mathrm{S}}$.

Figure 11 illustrates the results of the entire $S-N$ data for the two groups of specimens. It indicates that the fatigue resistance of group $A_{S}$ is superior to that of group $B_{S}$, i.e. the condition of smaller grain size possesses better fatigue life. The fatigue limit, which is defined as the maximum stress experienced by a specimen withstanding $5 \times 10^{6}$ loading cycles, is $368 \mathrm{MPa}$ for group $\mathrm{A}_{\mathrm{S}}$ and $299 \mathrm{MPa}$ for group $\mathrm{B}_{\mathrm{S}}$. The results of
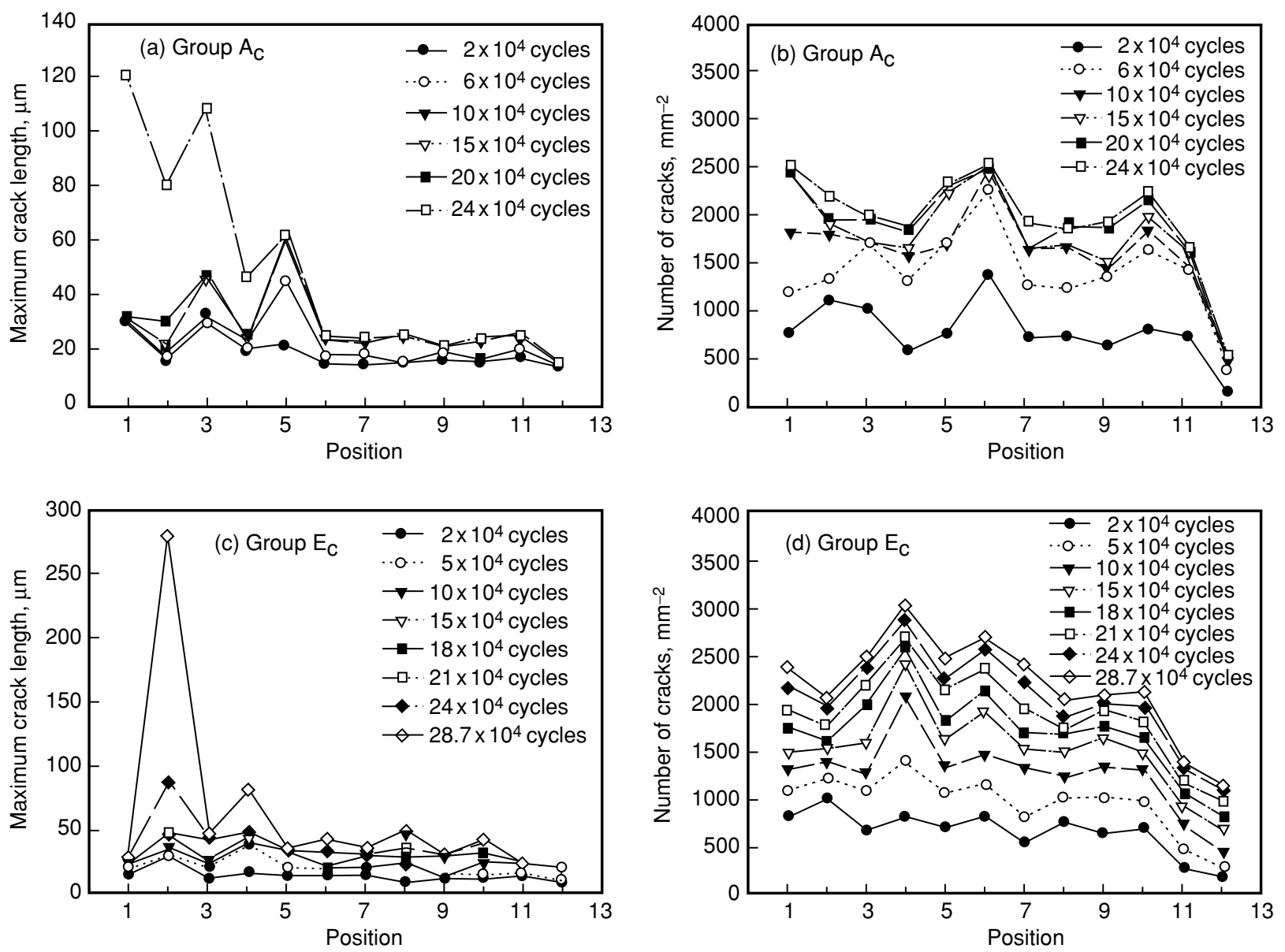

Fig. 9 Stochastic development of maximum crack length [(a) and (c)] and total number of cracks [(b) and (d)] for steels $A_{C}$ and $E_{C}$. 
(a)

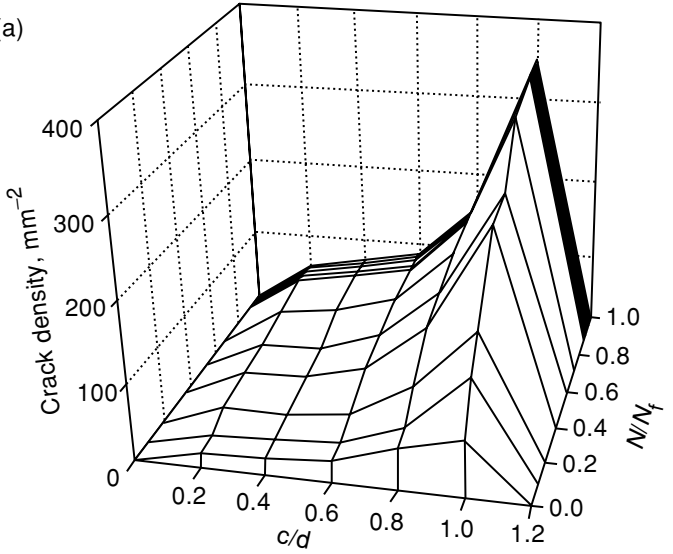

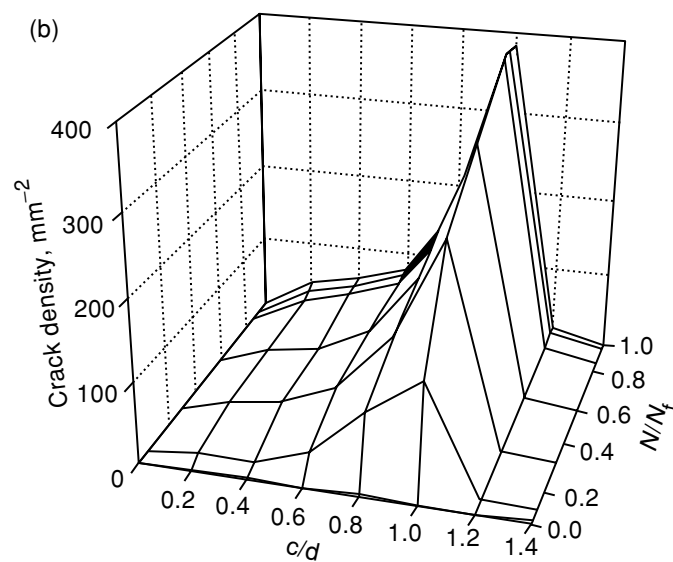

Fig. 10 Variation of number of cracks with normalized crack length and number of fatigue cycles. (a): Group $A_{S}$, and (b): group $B_{S}$.

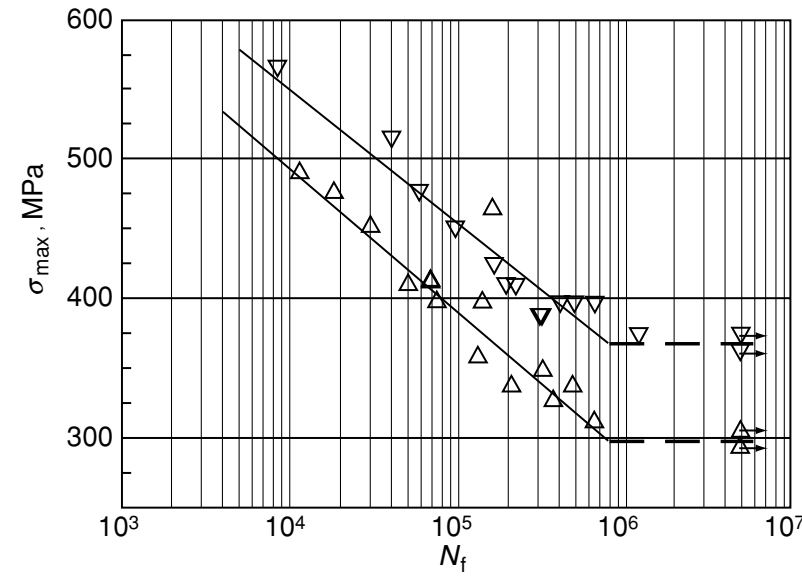

Fig. 11 Maximum applied stress vs. number of cycles to failure ( $\nabla$ : $d=72 \mu \mathrm{m}, \Delta: d=207 \mu \mathrm{m}$, symbol with arrow: no fracture occurred).

Fig. 12 show the variation of the total number of short cracks $\left(D_{0}\right)$ with normalized number of fatigue cycles. It is noticed that the difference between the two data sets diminishes despite their difference in grain size. A parabolic tendency exists between $D_{0}$ and $N / N_{\mathrm{f}}$, and the value of $D_{0}$ almost remains constant after the formation of a main crack. Referring to the linear correlation between $c_{\max }$ and $D_{0}$ indicated in Fig. 4 and noting that the normalized time $t$ is associated with normalized fatigue cycles $N / N_{\mathrm{f}}$, one may conclude that the variation trend of $c_{\max }$ with $t$ is equivalent to that of $D_{0}$ with $N / N_{\mathrm{f}}$. Thus, we see the evidence that the variation tendency between $c_{\max }$ and $t$ given by stochastic simulations shown in Fig. 3 is consistent with that of the experimental results shown in Fig. 12. The solid curve, plotted in Fig. 3 obtained by mean-field theory, overestimates the collective short crack evolution when $t$ tends to a large

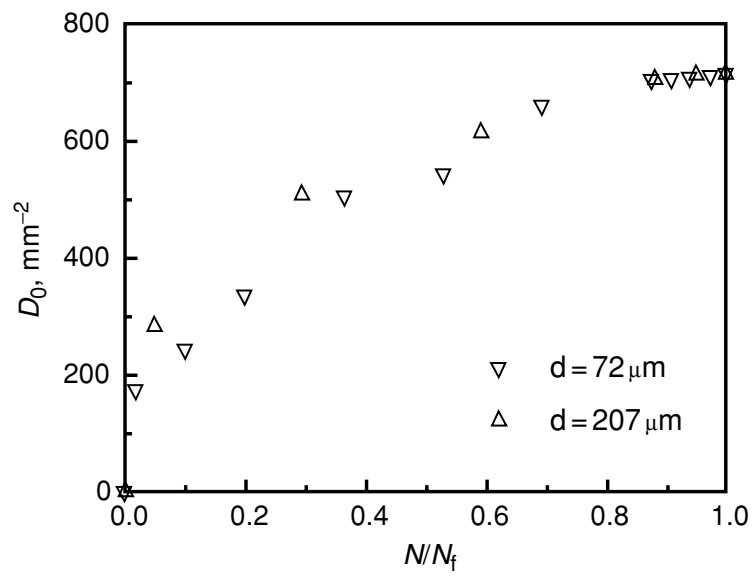

Fig. 12 Total number of short cracks $D_{0}$ vs. normalized number of fatigue cycles $N / N_{\mathrm{f}}$.

value. The parabolic increment between $D_{0}$ and $N / N_{\mathrm{f}}$ is also obvious for another type of specimens $\left(\mathrm{A}_{\mathrm{C}}, \mathrm{B}_{\mathrm{C}}\right.$, $\mathrm{C}_{\mathrm{C}}, \mathrm{D}_{\mathrm{C}}$ and $\mathrm{E}_{\mathrm{C}}$ ), which may be observed from Fig. $9 \mathrm{~b}$ and $\mathrm{d}$.

\section{CONCLUSIONS}

The stochastic simulations using the equilibrium equation of LCND have been conducted to display the random distribution of short crack population. The experiments on a series of structural steels and a stainless steel reveal the stochastic behaviour of short fatigue cracks. The following conclusions are drawn:

1 Stochastic characteristics prevail in the evolution process of short fatigue cracks. The local area with obvious short crack damage in the early cycling stage may not be the location of a main crack, while some local area with less 
short crack damage in the early cycling stage may become a location to form a main crack leading to final fracture.

2 At the early stage of fatigue cycling, the difference of simulations between stochastic analyses and the meanfield method is diminished. At a later stage of the fatigue process, the increment of short crack parameters slows down in comparison with the mean-field method. The experimental results of parabolic tendency between total number of cracks and fatigue cycles are consistent with the stochastic simulations.

3 In spite of the stochastic characteristics, the specimen condition of smaller grain size possesses better fatigue resistance and the specimen condition of less pearlite fraction is of superior fatigue properties.

\section{Acknowledgements}

This paper was supported by the National Science Foundation of China and the Chinese Academy of Sciences.

\section{REFERENCES}

1 Hong, Y., Lu, Y. and Zheng, Z. (1991) Orientation preference and fractal character of short fatigue cracks in a weld metal. $\mathcal{F}$. Mater. Sci. 26, 1821-1826.

2 Hong, Y., Gu, Z., Fang, B. and Bai Y. (1997) Collective evolution characteristics and computer simulation of short fatigue cracks. Phil. Mag. A. 75, 1517-1531.

3 Price, C. E. (1988) The progression of bending fatigue in nickel, Fatigue Fract. Engng Mater. Struct. 11, 483-492.

4 Weiss, J. and Pineau, A. (1993) Continuous and sequential multiaxial low-cycle fatigue damage in 316 stainless steel. In: Advance in Multiaxial Fatigue (eds D. L. McDowell and R. Ellis),
American Society for Testing and Materials, Philadelphia, pp. 183-203. ASTM STP 1191.

5 Suh, C. M., Lee, J. J., Kang, Y. G., Ahn, H. J. and Woo, B. C. (1992) A simulation of the fatigue crack process in type 304 stainless steel at $538{ }^{\circ}$ C. Fatigue Fract. Engng Mater. Struct. 15, 671-684.

6 Goto, M. (1994) Statistical investigation of the behaviour of small cracks and fatigue life in carbon steels with different ferrite grain sizes. Fatigue Fract. Engng Mater. Struct. 17, 635-649.

7 Hong, Y., Qiao, Y., Liu, N. and Zheng, X. (1998) Effect of grain size on collective damage of short fatigue cracks and fatigue life estimation for a stainless steel. Fatigue Fract. Engng Mater. Struct. 21, 1317-1325.

8 Fang, B., Hong, Y. and Bai, Y. (1995) Experimental and theoretical study on numerical density evolution of short fatigue cracks. ACTA Mechanica Sinica. (English Edition) 11, 144-152.

9 Qiao, Y. and Hong, Y. (1998) An analysis of collective damage for short fatigue cracks based on equilibrium of crack numerical density. Engng Fract. Mech. 59, 151-163.

10 Qiao, Y. and Hong, Y. (1998) A stochastic model for evolution of collective short-fatigue-cracks based on local field analysis. Acta Mechanica Sinica. 30, 564-571 (In Chinese).

11 Hong, Y. and Qiao, Y. (1998) Analysis of damage moments in the collective evolution of short fatigue cracks. Key Engng Mater. 145-149, 399-404.

12 Hong, Y., Lu, Y. and Zheng, Z. (1990) Short fatigue crack behaviour in iso-stress specimens. Acta Metall Sinica. 3A, 276-281.

13 Fu, M., Hong, Y. and Zheng, L. (1999) Two kinds of novel apparatus for fatigue test with plate-shape specimens. In: Fatigue '99, Proceedings of the Seventh International Fatigue Congress (eds Xue-Ren Wu and Zhong-Guang Wang). Higher Education Press, Beijing, China, Vol. 4, pp. 2767-2770. 